\title{
A retrospective analysis of personality disorder presentations in a Canadian university-affiliated hospital's emergency department
}

Sarah Penfold, Dianne Groll, Dane Mauer-Vakil, Jennifer Pikard, Megan Yang and Mir Nadeem Mazhar

\section{Background}

Individuals with personality disorders often have extensive involvement with healthcare services including frequent utilisation of emergency departments.

\section{Aims}

The aim of this study was to identify factors associated with emergency department presentations by individuals with personality disorders.

\section{Method}

A 12-month retrospective data analysis of all mental-healthrelated emergency department visits was performed. Age, gender, time and season of presentation, length of stay, mode of arrival and discharge arrangements for individuals with personality disorders were compared to individuals with other psychiatric diagnoses.

\section{Results}

There were 336 visits by individuals with personality disorders and 5290 visits by individuals with other psychiatric diagnoses.
Individuals with personality disorders were significantly more likely to be female, young adults, brought in by police, arrive in the evening, discharged home and have a longer median length of stay.

\section{Conclusion}

Knowing what factors are associated with emergency department presentations by individuals with personality disorders can help ensure that appropriately trained support staff are available.

\section{Declaration of interest}

None.

\section{Copyright and usage}

(C) The Royal College of Psychiatrists 2016. This is an open access article distributed under the terms of the Creative Commons Non-Commercial, No Derivatives (CC BY-NC-ND) license.

Stigma further complicates the interaction between the healthcare system and individuals with personality disorders. Recent evidence suggests that, among mental health patients, those with personality disorders are the most severely stigmatised ${ }^{12}$ and that mental health professionals such as psychiatric nurses and psychiatrists have negative attitudes towards, and less empathy for, individuals with personality disorders, and particularly with BPD. ${ }^{13,14}$ Provider stigma can have deleterious effects on the quality and accessibility of care for this population. ${ }^{15,16}$

Although the link between a personality disorder diagnosis and high utilisation of emergency psychiatry services is well established, little else is known with regard to how personalitydisorder-related presentations differ as compared with other mental health presentations in the emergency department. The aim of this study was to investigate whether factors such as mode of arrival, time and season of arrival, length of stay (LOS) and ultimate disposition decisions differ between individuals identified as having personality disorders versus individuals with other mental-health-related problems.

Based on clinical experience, we postulated the following: that individuals identified as having a personality disorder would be more likely to arrive outside the regular working hours of 09.00 to 17.00; that they would be more likely to be brought to hospital by police; and that they would be more likely to be discharged rather than admitted. We also postulated that those diagnosed with personality disorders would be younger, because prevalence of personality disorder has been found to decrease with age. ${ }^{17}$ Finally, we hypothesised that individuals with personality disorders would have more frequent emergency department presentations and were more likely to be female. ${ }^{1}$

The ability to identify factors associated with emergency department presentations by individuals with personality-disorder-related 
diagnoses could result in improved crisis management and emergency psychiatry services for these individuals.

\section{Method}

This is a retrospective study of all mental-health-related emergency department visits that occurred between 1 January and 31 December 2015 at the Kingston General Hospital. The Kingston General Hospital is a 440-bed, university-affiliated, tertiary care hospital in Southeastern Ontario, Canada, and serves a catchment area of approximately 500000 residents. ${ }^{18}$ Prior to commencement, this study underwent review for ethical compliance by the Queen's University Health Sciences and Affiliated Teaching Hospitals Research Ethics Board.

Individuals were included if their primary diagnosis on discharge from the emergency department was a psychiatric diagnosis. Diagnoses were coded according to the World Health Organization ICD-10 codes. Our study compared individuals diagnosed with personality disorders with those with all other psychiatric diagnoses (see Table 1 for included diagnoses).

Individuals with personality disorders were further subgrouped into four personality disorder types: (1) accentuation of personality traits; (2) emotionally unstable personality disorder; (3) dissocial personality disorder; and (4) 'other' personality disorders, which included paranoid, schizoid, histrionic, anankastic, anxious (avoidant), dependent, other, unspecified and mixed personality disorders.

Participant age was grouped into four categories: adolescent (12-17), young adult (18-24), adult (25-65) and senior (65+) Season of presentation was divided into Fall (September-November), Spring (March-May), Summer (June-August) and Winter (December-February). Time of presentation was coded as morning $(06.01 \mathrm{~h}$ to $12.00 \mathrm{~h})$, afternoon (12.01 h to $18.00 \mathrm{~h})$, evening $(18.01 \mathrm{~h}$ to $24.00 \mathrm{~h}$ ) or night-time $(24.01 \mathrm{~h}$ to $06.00 \mathrm{~h})$. Information regarding

\begin{tabular}{|c|c|}
\hline Diagnosis cluster & ICD-10 codes \\
\hline \multicolumn{2}{|l|}{ Personality disorder diagnosis } \\
\hline Dissocial personality disorder & F60.2 \\
\hline Emotionally unstable personality disorder & F60.3 \\
\hline Accentuation of personality traits & Z73.1 \\
\hline \multicolumn{2}{|l|}{ Other personality disorders: } \\
\hline i) Paranoid personality disorder & F60.0 \\
\hline ii) Schizoid personality disorder & F60.1 \\
\hline iii) Histrionic personality disorder & F60.4 \\
\hline iv) Anankastic personality disorder & F60.5 \\
\hline v) Anxious (avoidant) personality disorder & F60.6 \\
\hline vi) Other specific personality disorders & F60.8 \\
\hline vii) Personality disorder, unspecified & F60.9 \\
\hline viii) Mixed and other personality disorders & F61 \\
\hline \multicolumn{2}{|l|}{ Other psychiatric diagnoses } \\
\hline Organic, including symptomatic, mental disorders & F00-F09 \\
\hline $\begin{array}{l}\text { Mental and behavioural disorders because of } \\
\text { psychoactive substance use }\end{array}$ & F10-F19 \\
\hline Schizophrenia, schizotypal and delusional disorders & F20-F29 \\
\hline Mood (affective) disorders & F30-F39 \\
\hline Neurotic, stress-related and somatoform disorders & F40-F48 \\
\hline $\begin{array}{l}\text { Behavioural syndromes associated with physiological } \\
\text { disturbances and physical factors }\end{array}$ & F50-F59 \\
\hline Mental retardation & F70-F79 \\
\hline Disorders of psychological development & F80-F89 \\
\hline $\begin{array}{l}\text { Behavioural and emotional disorders with onset usually } \\
\text { occurring in childhood and adolescence }\end{array}$ & F90-F98 \\
\hline Unspecified mental disorder & F99-F99 \\
\hline
\end{tabular}

LOS in the emergency departments, gender, mode of arrival (walk-in, ambulance, police, combination of ambulance services or other) and disposition/discharge arrangements (discharge home, admission to hospital, left against medical advice/left without being seen, transfer to clinic and death after arrival) was also collected.

Data were analysed using SPSS v24. Data were described using frequencies, percentages, means and standard deviations. Relationships between all other psychiatric diagnoses and all personality disorder diagnoses were assessed using Mann-Whitney $U$ (age groups, LOS and frequency of visits) and chi-square (gender, mode of arrival, time of presentation, season and discharge disposition) analyses.

Comparisons between the different personality subgroup disorders were assessed using chi-square tests (gender, mode of arrival, time of presentation, season and discharge disposition) with post hoc testing using adjusted standardised residuals and Kruskal-Wallis $H$ tests (age groups, LOS and frequency of visits) with Bonferroni adjustments. Missing data were treated as missing and statistical significance was set at $P<0.05$.

\section{Results}

The final data set consisted of 5626 mental-health-related emergency department visits (336 for personality disorder presentation and 5290 for all other mental health presentations).

Of the 336 visits for personality disorder presentations, there were a total of 238 unique individuals who made one or more visits during the study period and a total of 3820 unique individuals who presented with another mental health presentation. The personality disorders visit group consisted predominantly of individuals presenting with accentuation of personality traits (39\%) and emotionally unstable personality disorder (40\%).

\section{Personality disorder diagnosis versus all other psychiatric diagnoses}

Table 2 shows the demographic information and the statistically significant differences between emergency department visits by individuals with any personality disorder diagnosis and those with any other psychiatric diagnosis.

Individuals with a personality disorder diagnosis were statistically significantly more likely to be female aged between 18 and 24, more likely to be brought in by the police and less likely to be brought in by ambulance. They are also more likely to arrive between $18.00 \mathrm{~h}$ and $24.00 \mathrm{~h}$ and to be discharged home. Individuals presenting with a personality disorder diagnosis also have a significantly longer median LOS in the emergency departments and make significantly more repeat visits.

\section{Differences between personality disorder subgroups}

Table 3 shows the demographic information regarding the personality disorder subgroups.

Gender

There were significantly more female emergency department visits for those presenting with emotionally unstable personality disorder as compared with all other personality disorder diagnoses $\left(\chi^{2}(3)=26.02, P<0.001\right)$.

\section{Age groups}

There were statistically significant differences in the adolescent age group between accentuation of personality traits and emotionally unstable personality disorder $(P=0.001)$. Significant differences were also identified among young adults between all groups $\chi^{2}(3)=8.197$, $P=0.042$. 


\begin{tabular}{|c|c|c|c|}
\hline & Personality disorder $n=336 N(\%)$ & Other mental health diagnosis $n=5290 \mathrm{~N}(\%)$ & Significance \\
\hline \multicolumn{4}{|l|}{ Gender } \\
\hline Male & 101 (30.1) & $2657(50.2)$ & \\
\hline Female & $235(69.9)$ & $2633(49.8)$ & $<0.001$ \\
\hline \multicolumn{4}{|l|}{ Age group } \\
\hline Adolescent (12-17) & $36(10.7)$ & $543(10.3)$ & $N / S$ \\
\hline Young adult (18-24) & $124(36.9)$ & $1162(22.0)$ & $<0.001$ \\
\hline Adult (25-64) & $171(50.9)$ & $2824(53.4)$ & $\mathrm{N} / \mathrm{S}$ \\
\hline Senior (65+) & $5(1.5)$ & $761(14.4)$ & $<0.001$ \\
\hline \multicolumn{4}{|l|}{ Mode of arrival in emergency departments } \\
\hline Walk-in & $157(46.7)$ & $2746(51.9)$ & $\mathrm{N} / \mathrm{S}$ \\
\hline Ambulance & $96(28.6)$ & 1959 (37.0) & 0.002 \\
\hline Police & $82(24.4)$ & 555 (10.5) & $<0.001$ \\
\hline Other & $1(0.3)$ & $30(0.6)$ & $N / S$ \\
\hline \multicolumn{4}{|l|}{ Time of presentation to emergency departments } \\
\hline Morning & $48(14.3)$ & $1053(20.0)$ & 0.01 \\
\hline Afternoon & $124(36.9)$ & 1867 (35.5) & N/S \\
\hline Evening & $124(36.9)$ & $1430(27.2)$ & $<0.001$ \\
\hline Night-time & $40(11.9)$ & 903 (17.2) & 0.012 \\
\hline \multicolumn{4}{|l|}{ Season of presentation to emergency departments } \\
\hline Spring & $74(22.0)$ & $1318(24.9)$ & $N / S$ \\
\hline Summer & $92(27.4)$ & $1350(25.5)$ & $N / S$ \\
\hline Fall & $94(28.0)$ & $1385(26.2)$ & $N / S$ \\
\hline Winter & $76(22.6)$ & $1237(23.4)$ & $\mathrm{N} / \mathrm{S}$ \\
\hline \multicolumn{4}{|l|}{ Discharge disposition from emergency departments } \\
\hline Discharge home & $251(74.7)$ & $3607(68.2)$ & 0.013 \\
\hline Admitted to hospital & $83(24.7)$ & $1499(28.3)$ & $\mathrm{N} / \mathrm{S}$ \\
\hline Left against medical advice or without being seen & $2(0.6)$ & $178(3.4)$ & 0.005 \\
\hline Transfer to clinic & $0(0)$ & $2(<0.0)$ & $\mathrm{N} / \mathrm{S}$ \\
\hline Death after arrival & $0(0)$ & $4(0.1)$ & $N / S$ \\
\hline \multicolumn{4}{|l|}{ Length of stay in emergency departments (hours) } \\
\hline Median (min, max) & $4.04(0.2,51.6)$ & $3.28(0,503)$ & $<0.001$ \\
\hline \multicolumn{4}{|l|}{ Multiple visits during study: } \\
\hline Mean (s.d.) number of visits & $3.75(6.82)$ & $1.42(1.58)$ & $<0.001$ \\
\hline
\end{tabular}

\section{Mode of arrival}

Significantly more individuals with accentuation of personality traits compared with those with emotionally unstable personality disorder $\left(\chi^{2}(3)=13.927, P=0.003\right)$ were walk-ins to the emergency departments. There were significantly more individuals with an emotionally unstable personality disorder compared with accentuation of personality traits visits who arrived by ambulance $\left(\chi^{2}(3)=\right.$ 14.833, $P<0.002)$.

\section{Time of presentation}

There were significantly more visits with the diagnosis of 'Other' compared with those with accentuation of personality traits and emotionally unstable personality disorder in the afternoons $\left(\chi^{2}(3)=14.911, P=0.002\right)$. Furthermore, there were significantly more emergency department visits with accentuation of personality traits compared with those with a diagnosis of 'Other' during the evenings $\left(\chi^{2}(3)=8.353, P=0.039\right)$.

\section{Frequency of emergency department visits}

Statistically significantly differences in frequency of emergency department visits during the 1-year study period were identified between 'Other' (mean=7.26 visits) and accentuation of personality traits (mean=1.93 visits), and between 'Other' and emotionally unstable personality disorder (mean $=3.85$ visits) $\left(\chi^{2}(3)=42.17\right.$, $P<0.001)$.
There were no statistically significant differences found in relation to LOS, season of presentation or disposition/discharge arrangements across personality disorder diagnosis categories.

\section{Discussion}

Although a number of studies have examined the demographic factors associated with individuals with psychiatric diagnoses who present frequently in the emergency department setting, ${ }^{10,19}$ this study examined factors associated with personality-disorderrelated presentations as compared with other psychiatric diagnoses.

Findings regarding increased frequency of emergency department presentation, increased likelihood of recurrent emergency department visits, and age and gender of individuals with personality disorders presenting to the emergency departments were consistent with previously published studies. ${ }^{1,5-11}$ Surprisingly, only $6 \%$ of mental-health-related presentations in the emergency departments involved individuals with a personality disorder diagnosis. Evidence suggests that personality disorder, in particular BPD, is 'markedly under-diagnosed'. ${ }^{20}$ A recent survey of psychiatrists practicing in the United States found that $57 \%$ had failed to disclose a diagnosis of BPD and $37 \%$ had failed to document a diagnosis of BPD at some point in their careers; the most common reasons for doing so were diagnostic uncertainty and concerns about stigma. ${ }^{21}$ It is possible that emergency department staff under-diagnose personality disorders for similar 


\begin{tabular}{|c|c|c|c|c|}
\hline & $\begin{array}{l}\text { Accentuation of personality } \\
\text { traits } n=131 \mathrm{~N}(\%)\end{array}$ & $\begin{array}{l}\text { Emotionally unstable personality } \\
\text { disorder } n=138 \mathrm{~N}(\%)\end{array}$ & $\begin{array}{l}\text { Dissocial personality } \\
\text { disorder } n=18 \mathrm{~N}(\%)\end{array}$ & $\begin{array}{l}\text { Other personality disorder } \\
\qquad n=51 \mathrm{~N}(\%)\end{array}$ \\
\hline \multicolumn{5}{|l|}{ Gender } \\
\hline Male & 48 (36.6) & $23(16.9)$ & $12(66.7)$ & 18 (35.3) \\
\hline Female & $83(63.4)$ & $113(83.1)$ & $6(33.3)$ & $33(64.7)$ \\
\hline \multicolumn{5}{|l|}{ Age group } \\
\hline Adolescent (12-17) & $25(19.1)$ & $6(4.4)$ & $2(11.1)$ & $3(5.9)$ \\
\hline Young adult (18-24) & $47(35.9)$ & $60(44.1)$ & $3(16.7)$ & $14(27.5)$ \\
\hline Adult (25-64) & $57(43.5)$ & $68(50.0)$ & $12(66.7)$ & $34(66.7)$ \\
\hline Senior (65+) & $2(1.5)$ & $2(1.5)$ & $1(5.6)$ & $0(0)$ \\
\hline \multicolumn{5}{|l|}{$\begin{array}{l}\text { Mode of arrival in emergency } \\
\text { departments }\end{array}$} \\
\hline Walk-in & $76(58.0)$ & $48(35.3)$ & $9(50.0)$ & $24(47.1)$ \\
\hline Ambulance & $29(22.1)$ & $54(39.7)$ & $2(11.1)$ & $11(21.6)$ \\
\hline Police & $26(19.8)$ & $33(24.3)$ & $7(38.9)$ & $16(31.4)$ \\
\hline Other & $0(0)$ & $1(0.7)$ & $0(0)$ & $0(0)$ \\
\hline \multicolumn{5}{|l|}{$\begin{array}{l}\text { Time of presentation to } \\
\text { emergency departments }\end{array}$} \\
\hline Morning & $18(13.7)$ & $19(14.0)$ & 4 (22.2) & $7(13.7)$ \\
\hline Afternoon & $41(31.3)$ & $46(33.8)$ & $6(33.3)$ & $31(60.8)$ \\
\hline Evening & $55(42.0)$ & $53(39.0)$ & $6(33.3)$ & $10(19.6)$ \\
\hline Night-time & $17(13.0)$ & $18(13.2)$ & $2(11.2)$ & $3(5.9)$ \\
\hline \multicolumn{5}{|l|}{$\begin{array}{l}\text { Season of presentation to } \\
\text { emergency departments }\end{array}$} \\
\hline Spring & $29(22.1)$ & $32(24.3)$ & 4 (22.2) & $9(17.6)$ \\
\hline summer & $38(29.0)$ & $30(22.1)$ & $3(16.7)$ & $21(41.2)$ \\
\hline Fall & $40(30.5)$ & $44(32.4)$ & $3(16.7)$ & $7(13.7)$ \\
\hline Winter & $24(18.3)$ & $30(22.1)$ & $8(44.4)$ & $14(27.5)$ \\
\hline \multicolumn{5}{|l|}{$\begin{array}{l}\text { Discharge disposition from } \\
\text { emergency departments }\end{array}$} \\
\hline Discharge home & $105(80.2)$ & $97(71.3)$ & $10(55.6)$ & 39 (76.5) \\
\hline Admitted to hospital & $24(24.7)$ & $39(28.7)$ & $8(44.4)$ & $12(23.5)$ \\
\hline $\begin{array}{l}\text { Left against medical advice or } \\
\text { without being seen }\end{array}$ & $2(0.1)$ & $0(0)$ & $0(0)$ & $0(0)$ \\
\hline Transfer to clinic & $0(0)$ & $0(0)$ & $0(0)$ & $0(0)$ \\
\hline Death after arrival & $0(0)$ & $0(0)$ & $0(0)$ & $0(0)$ \\
\hline \multicolumn{5}{|l|}{$\begin{array}{l}\text { Length of stay in emergency } \\
\text { departments (hours) }\end{array}$} \\
\hline Mean (s.d.) & $5.49(4.19)$ & $5.00(4.18)$ & $4.73(3.76)$ & $5.53(7.31)$ \\
\hline Multiple visits during study N (\%) & $114(87.0)$ & $65(47.8)$ & $12(66.7)$ & $46(90.2)$ \\
\hline Mean (s.d.) number of visits & $1.93(1.88)$ & $3.85(6.17)$ & $7.0(17.37)$ & $7.26(9.12)$ \\
\hline
\end{tabular}

reasons. Another possibility is that emergency department staff might view the assessment and diagnosis of personality disorders as existing outside of their scope of practice.

\section{Accentuation of personality traits}

In this study, the ICD-10 code 'accentuation of personality traits' was the most common personality-disorder-related diagnosis assigned in the emergency department setting. Interestingly, this code is not related to personality disorders, per se, it is located under the ICD-10 heading: 'Factors influencing health status and contact with health services'; subheading: 'Problems related to life-management difficulty'. ${ }^{22}$ The term is meant to be applied in cases in which 'Type A behaviours' such as 'ambition, a need for high achievement, impatience, competitiveness, and a sense of urgency' influence health status and contact with health services. ${ }^{22}$ It seems unlikely that individuals exhibiting these 'Type A behaviours' would present acutely in an emergency department setting. A more likely explanation would be that emergency room staff erroneously apply this diagnostic code when personality disorder traits or personality disorder is suspected, but a formal diagnosis is not assigned. This represents an opportunity for inter-professional collaboration and education regarding the appropriate use of ICD-10 codes related to mental health.

\section{Increased likelihood of presentation between $18.00 \mathrm{~h}$ and $24.00 \mathrm{~h}$}

Individuals presenting to the emergency departments in this study between $18.00 \mathrm{~h}$ and $24.00 \mathrm{~h}$ would have the following disadvantages compared with individuals presenting between, for example, $09.00 \mathrm{~h}$ and $17.00 \mathrm{~h}$ : (1) less access to social work/crisis support staff; (2) increased difficulty connecting to out-patient resources and community mental health teams outside clinic hours; and (3) logistical barriers to obtaining collateral information and to collaborating with community mental healthcare providers to assist with disposition planning.

It would be interesting to explore the reasons why personality disorder presentations were more likely to occur in the evening. Are interpersonal crises most likely to occur at this time? Do individuals feel less supported by community resources at night? Do they simply prefer to present at this time? It would be prudent to determine whether this finding is consistent in other emergency department settings, as this knowledge could assist in the 
development of personality-disorder-specific programming occurring outside regular clinic hours.

\section{Personality-disorder-related presentations more likely to be brought to emergency departments by police}

The increased likelihood of presenting to emergency departments with police is likely related to high rates of self-harm, para-suicidal behaviours, suicidal ideation and suicide attempts associated with BPD. Emotional dysregulation, impulsivity and anger are three core features of BPD that might also contribute to the higher likelihood of police involvement. This underscores the importance of liaison between emergency mental health services and police services.

\section{Decreased likelihood of admission}

The decreased likelihood of admission occurring with personalitydisorder-related presentations may be related to the fact that acute hospitalisation has not been shown to be effective in individuals with BPD. ${ }^{23}$ Both the American Psychiatric Association and the National Collaborating Centre for Mental Health (NICE) practice guidelines for the treatment of BPD suggest that hospitalisation is appropriate, as a last resort, to minimise harm for acutely suicidal individuals with $\mathrm{BPD}{ }^{24,25}$

\section{Strengths}

This study examined a number of variables associated with personality-disorder-related presentations that have not been explored previously in the emergency department setting, thereby addressing gaps in knowledge regarding an important diagnostic group. The inclusion of a comparison group further strengthened the study design.

\section{Limitations}

In this study, diagnoses were assigned by emergency department staff, rather than by mental health personnel or using validated diagnostic tools. This may have affected diagnostic accuracy. Given the high prevalence of personality disorders, and the finding that individuals with personality disorders are high utilisers of emergency department services, we suspect that personality disorders were under-diagnosed in the comparison group and that this could have affected our results. As diagnostic coding was based on the main presenting diagnosis assigned by emergency department staff, it has not been possible to assess comorbidity between personality disorders and other psychiatric diagnosis on the basis of available data, which could be considered another limitation of the study.

\section{Future areas of study/consideration}

The findings that individuals with personality disorders are more likely to present to emergency departments outside regular clinic hours, and are more likely to be brought to emergency departments by police, warrant further study to clarify, confirm and explore these factors. Ensuring that well-trained support staff are available in the emergency departments at times when individuals with personality disorders are most likely to present may help to better address the needs of this important diagnostic group. The above findings can also be used to make a stronger case for out-of-hours availability of other evidence-based support services such as home-based treatment and crisis resolution teams, emergency mental health housing and post-discharge follow-up services, which can divert some of these emergency department presentations and potentially reduce the need for unnecessary hospital admission.

Treatment-seeking individuals with personality disorders are more likely to experience stigma ${ }^{16}$ and may be further stigmatised in the emergency department setting, particularly if they are brought by police and present at times when there is limited access to mental health services. This could include more focus on educating out-ofhours emergency room staff on diagnosis and management of individuals with personality disorders including specific training on dialectical behaviour therapy and crisis management strategies. Personality-disorder-specific psychoeducation and anti-stigma programmes for front-line workers in the emergency department could potentially improve the quality of care that treatment-seeking individuals with personality disorder receive in this setting.

Sarah Penfold, MD, Department of Psychiatry, Queen's University, Kingston, Ontario Canada; Dianne Groll, PhD, Department of Psychiatry, Queen's University, Kingston, Ontario, Canada; Dane Mauer-Vakil, BKin, Department of Psychiatry, Queen's University, Kingston, Ontario, Canada; Jennifer Pikard, MD, Department of Psychiatry, Queen's University, Kingston, Ontario, Canada; Megan Yang, MD, Department of Psychiatry, Queen's University, Kingston, Ontario, Canada; Mir Nadeem Mazhar, FRCPsych, FRCPC, DABPN, Department of Psychiatry, Queen's University, Kingston, Ontario, Canada

Correspondence: Mir Nadeem Mazhar, Department of Psychiatry, Queen's University, Kingston, Ontario, Canada. Email: mazharm@kgh.kari.net

First received 5 Sep 2016, final revision 21 Nov 2016, accepted 23 Nov 2016

\section{References}

1 Tyrer P, Reed G, Crawford M. Classification, assessment, prevalence, and effect of personality disorder. Lancet 2015; 385: 717-26.

2 Lenzenweger M. Epidemiology of personality disorders. Psychiatr Clin North Am 2008; 31: 395-403

3 Moran P. The prevalence of personality disorder among UK primary care attenders. Acta Psychiatr Scand 2000; 102: 52-7.

4 Bender D, Dolan R, Skodol A, Sanislow C, Dyck I, McGlashan T, et al. Treatment utilization by patients with personality disorders. Am J Psychiatry 2001; 158 295-302.

5 Chang G, Weiss A, Orav E, Rauch S. Predictors of frequent emergency department use among patients with psychiatric illness. Gen Hosp Psychiatry 2014; 36 716-20

6 Boyer L, Dassa D, Belzeaux R, Henry J, Samuelian J, Baumstarck-Barrau K. Frequent visits to a French psychiatric emergency service: diagnostic variability in psychotic disorders. Psychiatr Serv 2011; 62: 966-70.

7 Sullivan P, Bulik C, Forman S, Mezzich J. Characteristics of repeat users of a psychiatric emergency service. Hosp Community Psychiatry 1993; 44: 376-80.

8 Pasic J, Russo J, Roy-Byrne P. High utilizers of psychiatric emergency services Psychiatr Serv 2005; 56: 678-84.

9 Schmoll S, Boyer L, Henry J, Belzeaux R. Frequent visitors to psychiatric emergency service: demographical and clinical analysis. L'Encephale 2015; 41 $123-9$.

10 Richard-Lepouriel $\mathrm{H}$, Weber $\mathrm{K}$, Baertschi $\mathrm{M}$, DiGiorigio $\mathrm{S}$, Sarasin $\mathrm{F}$, Canuto A. Predictors of recurrent use of psychiatric emergency services. Psychiatr Serv 2015; 66: 521-6.

11 Vandyk D, VanDenKerkhof E, Graham I, Harrison M. Profiling frequent presenters to the emergency department for mental health complaints: socio-demographic, clinical, and service use characteristics. Arch Psychiatr Nurs 2014; 28: 420-5.

12 Catthoor K, Schrijvers D, Hutsebaut J, Feenstra D, Sabbe B. Psychiatric stigma in treatment-seeking adults with personality problems: evidence from a sample of 214 patients. Front Psychiatry 2015; 6: 101

13 Bodner E, Cohen-Fridel S, Mashiah M, Segal M, Grinshphoon A, Fischel T, et al. The attitudes of psychiatric hospital staff toward hospitalization and treatment of patients with borderline personality disorder. BMC Psychiatry 2015; 15: 2.

14 Sansone R, Sansone L. Responses of mental health clinicians to patients with borderline personality disorder. Innov Clin Neurosci 2013; 10: 39-42.

15 Lawn S, Mcmahon J. Experiences of care by Australians with a diagnosis of borderline personality disorder. J Psychiatr Ment Health Nurs 2015; 22 $510-21$

16 Sheehan L, Nieweglowski K, Corrigan P. The stigma of personality disorders. Curr Psychiatry Rep 2016; 18: 1-7.

17 Balsis $\mathrm{S}$, Gleason $\mathrm{M}$, Woods $\mathrm{C}$. An item response theory analysis of DSM-IV personality disorder criteria across younger and older age groups. Psychol Aging 2007; 22: 171-85. 
18 Kingston General Hospital. KHG Quick Facts (http://www.kgh.on.ca/about-kgh/ kgh-quick-facts accessed 21 Oct 2016)

19 Lim MH. A psychiatric emergency clinic: a study of attendances over six months. Br J Psychiatry 1983; 143: 460-6.

20 Comtois K, Carmel A. Borderline personality disorder and high utilization of inpatient psychiatric hospitalization: concordance between research and clinica diagnosis. J Behav Health Serv Res 2016; 43: 272-80.

21 Sisti D, Segal AG, Siegel AM, Johnson R, Gunderson J. Diagnosing, disclosing, and documenting borderline personality disorder: a survey of psychiatrists' practices. J Pers Disord 2016; 30: 848-56.

22 World Health Organization. The ICD-10 Classification of Mental and Behavioural Disorders: Clinical Descriptions and Diagnostic guidelines. WHO, 1992
23 Paris J. Is hospitalization useful for suicidal patients with borderline personality disorder?J Pers Disord 2004; 18: 240-7.

24 American Psychiatric Association. Practice guideline for the treatment of patients with borderline personality disorder. Am J Psychiatry 2001; 158: 1-52.

25 National Collaborating Centre for Mental Health. Borderline Personality Disorder: Treatment and Management. The British Psychological Society and the Royal College of Psychiatrists, 2009. 